\title{
ETIQUETAS TÉCNICAS E SUA IMPORTÂNCIA PARA OS USUÁRIOS PROFISSIONAIS NA PRESTAÇÃO DE SERVIÇOS DE CUIDADOS TÊXTEIS ESPECIALIZADOS: UMA ANÁLISE EXPLORATÓRIA
}

TECHNICAL LABELS AND ITS IMPORTANCE FOR PROFESSIONAL USERS IN THE PROVISION OF SPECIALIZED TEXTILE CARE SERVICES: AN EXPLORATORY ANALYSIS

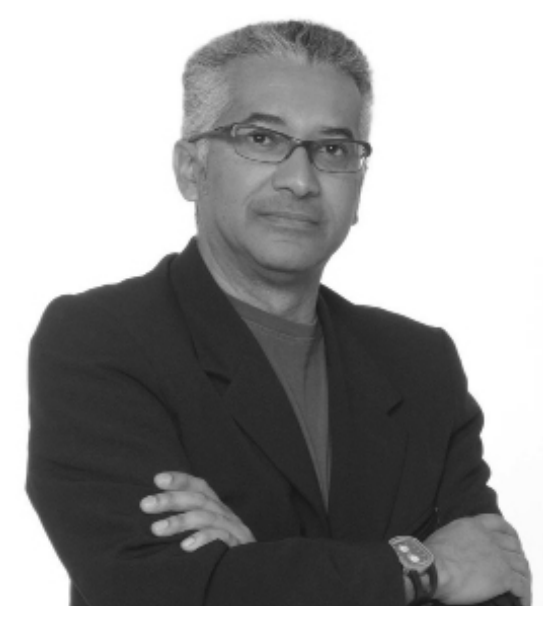

\section{Célio Teodorico dos Santos}

Doutor em Engenharia Mecânica pela Universidade Federal de Santa Cararina

Professor Adjunto do Departamento de Design da Universidade Federal de Santa Cararina celio.teodorico@gmail.com

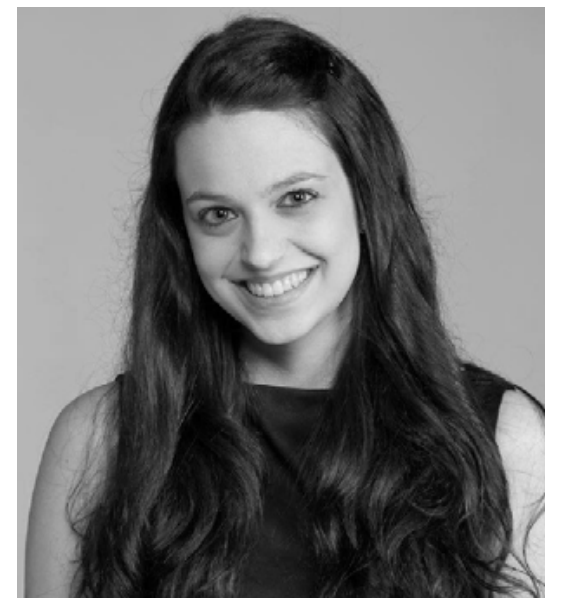

\section{Jessica Schneider}

Mestre em Design pela Universidade do Estado de Santa Catarina

Pesquisadora e membro do Núcleo de Estudos Semióticos Transdisciplinares - NEST jessica_schneider@outlook.com 


\section{RESUMO}

As etiquetas têxteis são consideradas instrumento comunicacional primordial no repasse de informações acerca das características de um determinado artigo têxtil para seus usuários. Esse artefato é essencial, principalmente, para os chamados usuários profissionais categorizados aqui como prestadores de serviços de cuidados têxteis especializados. Deste modo, esse artigo se estrutura a partir da análise exploratória das interações entre esses usuários e as etiquetas técnicas de manutenção e conservação têxtil, com o objetivo de verificar a importância informacional de tais etiquetas para prestação dos serviços de cuidados têxteis especializados. Como critério de investigação foi estipulada uma abordagem com delineamento analítico e descritivo a partir de coleta de dados qualitativos realizada por meio de entrevistas semiestruturadas com seis (06) usuários profissionais atuantes no setor de serviços de cuidados têxteis especializados - lavanderias. Os resultados evidenciam certo descuido e inadequação no arranjo projetual das etiquetas, que ocasionam interações incorretas e insatisfatórias para os usuários profissionais, impedindo o acesso à informação e favorecendo o rejeito das etiquetas.

\section{PALAVRAS-CHAVE:}

Etiquetas Têxteis. Interações Interfaciais. Usuário Profissional.

\section{ABSTRACT}

Textile labels are considered primary communication tool in the transfer of information about the characteristics of a particular textile item to its users. This artifact is essential, especially for so-called professional users, here categorized as specialized textile care service providers. Thus, this article is structured from the exploratory analysis of the interactions between professional users and textile maintenance and conservation technical labels, in order to verify the informational importance of these labels for provision of specialized textile care services. As research criteria was set approach with analytical and descriptive design from qualitative data collection conducted through semi-structured interviews with six (06) professional users working in the specialized textile care services sector - laundries. The results show a certain carelessness and inadequate in projetual arrangement of labels that cause incorrect interactions and unsatisfactory for professional users, preventing access to information and encouraging the waste of textile labels. 


\section{KEYWORDS}

Textile Labels. Interfacial Interactions. Professional User.

\section{INTRODUÇÃO}

As etiquetas técnicas de manutenção e conservação têxtil se configuram como instrumento essencial no repasse de informações acerca das características específicas de um determinado artigo têxtil. Assim como um manual de instrução de um produto diverso, as etiquetas interagem como meio de comunicação entre fabricantes e usuários. $\mathrm{O}$ advento da tecnologia têxtil e o surgimento de novas fibras sintéticas e artificiais, bem como o aumento crescente de exportações e importações de artigos têxteis e ainda, a modernização do maquinário de cuidados têxteis, como lavadoras e secadoras eletroeletrônicas e ferros de passar com termostato e à vapor, foram algumas das circunstâncias que exigiram a providencia de informações de cunho técnico aos usuários de artigos têxteis (SIROTTI, 2000).

Novas fibras e tecidos tecnológicos são elaborados continuamente e utilizados na fabricação de artigos têxteis, consumidos por uma sociedade que, em sua maioria, não possui conhecimento técnico, ou seja, que até muito tempo só soube manter e cuidar de artigos têxteis fabricados a partir de fibras naturais com conhecimento cultural advindo de práticas da vida diária passadas de geração em geração. A tecnologia têxtil industrial permitiu que o universo de fibras têxteis fosse ampliado de forma que a variedade existente de tecidos se torne extremamente numerosa e com características físicas, como toque, textura e aparência semelhantes às fibras naturais (PEZZOLO, 2007; SIROTTI, 2000). Nesse sentido, a origem e surgimento da etiqueta técnica afixada ao artigo têxtil residiu na necessidade de disponibilização de informações básicas de cuidados têxteis de artigos confeccionados com tecidos e fibras que não já não são mais reconhecidos por meio da inspeção visual ou tátil.

A etiqueta técnica, também conhecida como etiqueta de manutenção e conservação têxtil tem o objetivo de comunicar o usuário, indicando as características e informações básicas do produto acerca do fabricante, composição têxtil, tamanho/dimensão, país de origem e procedimentos para cuidados e tratamentos têxteis. É o único modelo de etiqueta que possui a obrigatoriedade de ser afixada em qualquer artigo têxtil, sendo a única também, a possuir uma regulamentação acerca das informações exigidas e suas disposições, o que evidencia sua importância para consumidores e usuários (JONES, 2005). Tal etiqueta, de certo modo, incentiva ainda, a preservação de credibilidade e valor 
simbólico de marca, proporcionados por outras categorias de etiquetas, como as promocionais e institucionais.

No Brasil, as etiquetas técnicas de manutenção e conservação têxtil são regulamentadas pelo Conselho Nacional de Metrologia, Normalização e Qualidade Industrial - CONMETRO e pelo Instituto Nacional de Metrologia, Qualidade e Tecnologia - INMETRO, sendo a primeira instituição autora da Resolução n 02, de 06 de maio de 2008, que dispõe sobre a aprovação e atualização do Regulamento Técnico Mercosul Sobre Etiquetagem de Produtos Têxteis e a segunda instituição responsável pela fiscalização e coleta de amostras para verificação da veracidade das informações contidas nas etiquetas, principalmente relativas à composição e procedimentos de manutenção e conservação têxtil (CONMETRO, 2008). As informações a respeito dos tratamentos de cuidado dos artigos têxteis são regulamentadas pela norma da ABNT NBR NM ISO 3758 (2013). A proposição principal da regulamentação de simbologia própria para manutenção têxtil é de padronizar os ícones com objetivo de fazer com que os códigos sejam facilmente compreensíveis e de fácil reconhecimento para o usuário (ABNT NBR NM ISO 3758, 2013). A aplicação da regulamentação imposta e das informações obrigatórias em uma etiqueta pode ser observada pela exemplificação apresentada na Figura 1.

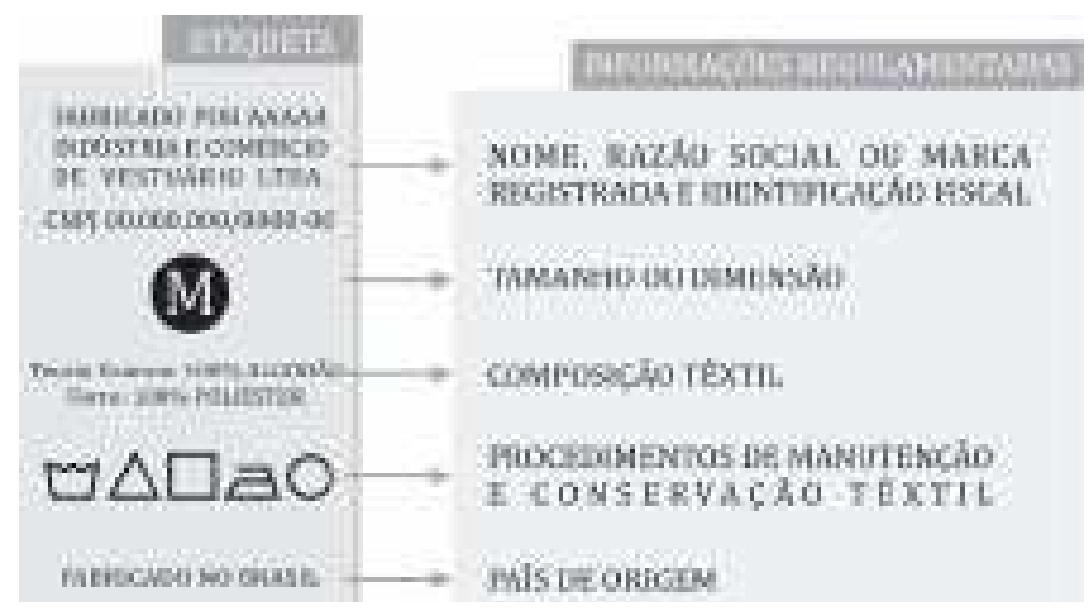

Figura 1 - Exemplificação da aplicação da regulamentação de etiquetagem têxtil. Fonte: Adaptado de Garcia et al., 2012, p. 3.

Tais informações obrigatórias devem ser apresentadas em idioma nacional português, inclusive em produtos importados, e podem ser indicadas por meio de uma ou mais etiquetas, selos, rótulos, decalques, carimbos, estampagem e/ ou similares, levando em consideração a adequação ao produto e satisfazendo aos requisitos de indelebilidade e afixação em caráter permanente. Em relação 
à localização das etiquetas nos artigos têxteis, a regulamentação não determina a obrigatoriedade de locais pré-determinados para artigos específicos, todavia, salienta que a etiqueta deve ser afixada preferencialmente em local de fácil visualização e em cada unidade ou fração do produto (CONMETRO, 2008). Percebe-se, como pesquisadores da área em contato direto com indústrias e marcas de artigos têxteis, que os aviamentos como etiquetas, lacres, pingentes e tags decorativos são altamente difundidos e amplamente utilizados, principalmente em artigos de vestuário, como forma de identificar a marca e investir nas características do produto que aparentemente são relevantes para o usuário, enquanto consumidor. O processo projetual de tais 'etiquetas', na qualidade de uma interface ornamental e estética, faz uso de tecnologias avançadas em uma produção cuidadosamente planejada com aplicações de insumos, matéria-prima e equipamentos de alta qualidade, de forma a obter uma gama diversificada de elementos, como texturas, cores e padronagens, que intencionam diferenciar o produto e assegurar a autenticidade da marca.

Entretanto, as etiquetas técnicas de manutenção e conservação têxtil parecem não alcançar tanta importância e consequentemente não recebem o mesmo cuidado e zelo projetual que as etiquetas institucionais e/ou promocionais. Parece haver um pensamento intrínseco generalizado por parte das indústrias e marcas de produtos têxteis de que tais etiquetas não são relevantes, principalmente nos quesitos comerciais e mercadológicos, e justamente por isso, não necessitam destaque, sendo somente necessárias devido às regulamentações e legislações impostas.

Tal despreocupação no projeto e elaboração de etiquetas técnicas de manutenção e conservação têxtil acaba por desfavorecer essa interface usuário-produto, que devido a sua ilegibilidade, irregularidade, desconforto em contato direto com o corpo e falta de padronização, se torna um meio de informação subestimada pelo usuário doméstico, que acaba por considerar as etiquetas técnicas dispensáveis. Todavia, tais etiquetas se tornam fundamentais ainda para os usuários considerados profissionais, ou seja, as empresas de cuidados têxteis especializados - lavanderias - que necessitam que sua interface seja principalmente legível, indelével e padronizada para o apropriado repasse das informações que, nesse sentido, garantem a correta prestação de seus serviços especializados.

A partir de uma revisão bibliográfica, verificou-se que as análises e avaliações referentes à interface etiqueta e usuário doméstico são contempladas por grande parte das pesquisas recentes relacionados à temática, como visto nos estudos 
realizados por Steyn et al. (2011); Garcia et al. (2012); Calisir et al. (2013); Merwe et al. (2013); Mupfumira e Jinga (2013), Nunes, Trotta e Licheski (2014). Estudos isolados, como por exemplo, os conduzidos por Feltham e Martin (2006); Pereira et al. (2014) utilizam em seus experimentos participantes considerados usuários profissionais/especialistas, entretanto, a definição e caracterização do perfil de tais sujeitos é pouco preciso. O estudo de Pereira et al. (2014) contempla um grupo de usuários especialistas, que são caracterizados como profissionais com experiência na área de moda/vestuário, enquanto o estudo de Feltham e Martin (2006) especifica os usuários profissionais como sendo indivíduos do gênero feminino, responsáveis pela compra e cuidados dos itens de vestuário no âmbito familiar. Não foram encontrados estudos que abordassem a temática das etiquetas técnicas com intuito de analisar sua interface junto aos usuários profissionais inseridos no contexto especializado das lavanderias. Apesar da importância comunicacional do artefato etiqueta para prestação de serviços de cuidados têxteis especializados, a carência na existência de estudos que abordem a temática das etiquetas têxteis inseridas no âmbito profissional dificulta o entendimento das interações existentes entre interface-usuário. Nesse sentido, o objetivo deste estudo residiu na análise perceptiva das interações entre usuários profissionais e etiquetas técnicas têxteis e na verificação da importância informacional de tais etiquetas para prestação dos serviços de cuidados têxteis especializados.

\section{MÉTODO}

\subsection{Delineamento Metodológico}

Esta pesquisa se estrutura a partir de um diagnóstico generalizado das percepções dos usuários profissionais acerca das suas interações interfaciais com as etiquetas técnicas de manutenção e conservação têxtil. Trata-se de um estudo com delineamento descritivo, com coleta de dados qualitativos, uma vez que procurou analisar e interpretar aspectos complexos e subjetivos relacionados ao comportamento humano, a partir da aplicação de entrevistas semiestruturadas. Quanto aos procedimentos, a pesquisa envolveu levantamento analítico, nesse caso, buscou-se a coleta de dados por meio de entrevistas com amostragens da população de usuários profissionais que tiveram experiências práticas com o problema pesquisado a fim de estabelecer um panorama global acerca das interações interfaciais existentes entre esses usuários e etiquetas têxteis. Por fim, o local de realização da pesquisa é de campo, por se constituir 
de investigação empírica realizada no local onde ocorre ou ocorreu um fenômeno ou que dispõe de elementos para explicá-los, procedendo dessa maneira à observação de fatos e fenômenos reais estabelecidos na interação entre usuários profissionais e a interface comunicacional estabelecida com as etiquetas técnicas de manutenção e conservação têxtil.

\subsection{População e Amostra}

A população-alvo desta etapa da pesquisa consistiu em profissionais atuantes em empresas que forneçam serviços de cuidados têxteis especializados, usualmente, conhecidas como lavanderias. A amostra, nesse caso, foi selecionada por julgamento e conveniência, e o recrutamento dos participantes se deu via telefone, e-mail ou de forma pessoal. Os critérios de inclusão compreendiam indivíduos maiores de 18 anos, com residência fixa na Grande Florianópolis, com experiência profissional, de no mínimo um (01) ano, na área de serviços de cuidados têxteis especializados.

Foi feito, inicialmente, um levantamento das lavanderias existentes e atuantes na Grande Florianópolis. Destas, foram selecionadas as lavanderias instaladas nos bairros que tangenciam as proximidades da UDESC — local de realização das entrevistas. Aproximadamente quinze (15) profissionais de tais lavanderias foram abordados e contatados para realização das entrevistas, entretanto, apenas seis (6) concordaram em participar da pesquisa.

O número da amostra foi definido, devido às dificuldades de acesso aos profissionais, em virtude da estrutura organizacional de cada estabelecimento, nos quais os profissionais contatados eram recepcionistas ou auxiliares de atendimento ao público, e pouco conheciam sobre os processos envolvidos na oferta de seus serviços, que em algumas lavanderias, ainda, eram terceirizados. Além disso, alguns profissionais se sentiram incapacitados e outros desconfortáveis em participar da pesquisa, dado que, isso implicaria a divulgação de informações e/ou opiniões referentes aos serviços por eles realizados. Por fim, houve casos de profissionais que não receberam autorização de seus chefes imediatos, ou dos proprietários das lavanderias onde trabalhavam. Observando que a amostra se compatibiliza com os requisitos de representatividade, nos quais não foram realizadas avaliações abrangendo dados quantitativos complexos, considerou-se válido o total de seis (06) indivíduos para análise íntegra das possíveis convergências e divergências dos dados qualitativos obtidos nesta etapa da pesquisa. 


\subsection{Instrumento de Coleta de Dados}

Considerou-se, para esta pesquisa, o método de entrevista semiestruturada, estabelecido por meio de um roteiro fundamentado por aproximadamente vinte (20) questionamentos sobre as percepções de interações interfaciais, estabelecidas entre o usuário profissional e as etiquetas técnicas de manutenção e conservação têxtil. A entrevista é um método de inquirição constituída num formato de interação social por meio de diálogos assimétricos, em busca de fontes de informação para coleta de dados (MORAES; MONT'ALVÃO, 2003). Segundo Jordan (1998), esse método é versátil que devido ao seu caráter de aplicação face-to-face, com a presença de um moderador ou investigador, minimiza a possibilidade de interpretações equivocadas dos questionamentos por parte do participante. A entrevista semiestruturada é conceituada como aquela na qual se tem uma ideia clara da temática a ser pesquisada, e aquela em que se tem uma ideia fundamentada a partir de um roteiro sistemático e específico de questionamentos (JORDAN, 1998). Nesta pesquisa, todavia, os questionamentos temáticos se constituem de caráter aberto, exceto na abordagem específica para o perfil sociodemográfico do participante. As questões foram baseadas a partir das discussões provenientes da revisão bibliográfica realizada, assim como da observação empírica e crítica da pesquisadora, uma vez que não foi encontrada bibliografia específica que analisasse as etiquetas têxteis com usuários profissionais atuantes em lavanderias.

Nesse sentido, os questionamentos foram divididos em quatro abordagens distintas, sendo: a) perfil sociodemográfico e descrição das atividades profissionais; b) percepções e interações interfaciais estabelecidas com as etiquetas técnicas de manutenção e conservação têxtil inseridas no contexto profissional das lavanderias; c) percepções e interações interfaciais acerca das características morfológicas e das informações normatizadas nas etiquetas técnicas de manutenção e conservação têxtil; e d) percepção da importância das etiquetas técnicas de manutenção e conservação têxtil para a prestação dos serviços especializados de cuidados têxteis.

A escolha da entrevista, em oposição a outros métodos de inquirição, se deu devido ao caráter exploratório desta pesquisa. Ainda, considerando que o usuário profissional também é um usuário doméstico, o método da entrevista permitiu, a partir do acompanhamento de um moderador, conduzir os questionamentos, convergindo e filtrando o compartilhamento de opiniões estritamente profissionais, sem que houvesse conflitos, por parte dos participantes, de suas visões enquanto usuários domésticos. 


\subsection{Procedimento de Coleta de Dados}

Esta pesquisa foi submetida e aprovada pelo Comitê de Ética em Pesquisas Envolvendo Seres Humanos - CEPSH/UDESC, conforme Resolução n 466, de 12 de dezembro de 2012/CNS/MS/CONEP, no dia 09 de dezembro de 2015, sob parecer consubstanciado do CEPSH no 1.357.947, CAAE n 51375115.0.0000.0118. Foram esclarecidos para os participantes os possíveis riscos e benefícios em relação à sua participação nos procedimentos experimentais e exploratórios desta pesquisa, assim como foi elucidado que sua participação era voluntária, anônima e não obrigatória, sendo dada a liberdade de desistência a qualquer momento, sem necessidade de preenchimento ou cooperação em todas as etapas de pesquisa previstas. Estimou-se que os riscos desta pesquisa se caracterizavam como mínimos, uma vez que as entrevistas não envolviam procedimentos invasivos ou que poderiam acarretar algum envolvimento emocional severo dos participantes.

As entrevistas semiestruturadas foram realizadas com seis (06) usuários profissionais, que se dispuseram em participar dos procedimentos integralmente, entre os dias 18 de março e 04 de abril de 2016, no Laboratório de Pesquisa em Design de Interações, nas dependências do CEART da UDESC. As entrevistas foram agendadas previamente via telefone e/ou e-mail pessoal, sendo realizadas individualmente, face-to-face, com a presença somente de um moderador - no caso, os pesquisadores - com duração média de aproximadamente trinta (30) minutos. As entrevistas foram gravadas somente em áudio, com auxílio de um gravador de voz digital marca Sony ICD-PX240, de modo a facilitar a transcrição dos dados com maior integridade.

As entrevistas foram conduzidas com base nos questionamentos fundamentados no roteiro, de maneira flexível, que variava de acordo com os caminhos e características de resposta de cada participante. Os questionamentos eram lidos separadamente em voz alta e com conotação informal, de modo a não apresentar termos muito técnicos ou científicos que dificultasse a compreensão dos participantes.

\subsection{Categorização, Análise e Tratamento dos Dados}

As entrevistas semiestruturadas foram transcritas com integridade, devido às gravações de áudio realizadas, e tabuladas manualmente com auxílio dos softwares Microsoft Word e Excel 2013. Os dados foram analisados, comparados e categorizados dentro das abordagens apresentadas anteriormente, as quais foram exploradas por meio da 'análise de conteúdo ', utilizadas para dados qualitativos que "considera a presença ou a ausência de uma dada característica de conteúdo ou 
conjunto de características num determinado fragmento da mensagem" (LIMA, 1993, p. 54). Nesta pesquisa, a análise do conteúdo consistiu do seguimento das etapas de categorização, inferência e interpretação, que compreendem o método linear de identificação das categorias de análise; sistematização e filtragem dos dados obtidos por meio das categorias específicas; e estabelecimento de comparações semânticas e conceituais respaldadas no referencial teórico (MEIRELES; CENDÓN, 2010). Dessa maneira, dentro de cada abordagem, foram identificadas as convergências e divergências entre as conceituações das respostas dos participantes.

\section{RESULTADOS E DISCUSSÃO}

Os resultados das análises dos dados, retirados das entrevistas semiestruturadas, serão apresentados e discutidos separadamente por meio de quatro abordagens categorizadas, as quais foram exibidas anteriormente.

\subsection{Perfil Sociodemográfico e Descrição das Atividades Profissionais}

No total, foram entrevistados seis usuários profissionais - quatro do gênero feminino e dois do gênero masculino, com idades entre 27 e 60 anos - atuantes no âmbito de serviços de cuidados têxteis especializados — lavanderias. Da posição/cargo que esses indivíduos ocupam profissionalmente, nas lavanderias, quatro são sócios-proprietários, um é supervisor técnico e o outro, atendente. Desses entrevistados, todos possuíam, ao menos, um ano de experiência no ramo de lavanderias, sendo dois deles, com experiência superior de cinco anos. Ainda, todos os entrevistados tinham, no mínimo, o ensino médio completo, sendo, um deles com ensino superior e dois com especialização/pós-graduação. As informações sociodemográficas da amostra de entrevistados podem ser visualizadas, adequadamente, no Quadro 1.

\begin{tabular}{|c|l|l|l|l|l|}
\hline ID & IDADE & SEXO & ESCOLARIDADE & CARGO/POSIÇÃO & EXPERIÊNCIA \\
\hline L01 & 27 & M & Ensino Médio & $\begin{array}{l}\text { Sócio proprietário } \\
\text { da Lavanderia }\end{array}$ & 2 anos \\
\hline L02 & 45 & F & Pós-Graduação & $\begin{array}{l}\text { Sócio Proprietária } \\
\text { da Lavanderia }\end{array}$ & 2 anos \\
\hline L03 & 35 & F & Ensino Médio & $\begin{array}{l}\text { Supervisora da } \\
\text { Lavanderia }\end{array}$ & 8 anos \\
\hline
\end{tabular}




\begin{tabular}{|l|l|l|l|l|l|}
\hline L04 & 60 & F & Especialização & $\begin{array}{l}\text { Sócia Proprietária } \\
\text { da lavanderia }\end{array}$ & 1 ano \\
\hline L05 & 45 & M & Ensino-Superior & $\begin{array}{l}\text { Sócio proprietário } \\
\text { da Lavanderia }\end{array}$ & 21 anos \\
\hline L06 & 30 & F & Ensino Médio & $\begin{array}{l}\text { Atendente da } \\
\text { Lavanderia }\end{array}$ & 1 ano \\
\hline
\end{tabular}

Fonte: Elaborado pelos autores, 2016.

A respeito das características geográficas das lavanderias, onde atuam os entrevistados, todas elas se localizam na cidade de Florianópolis, cinco delas em bairros centrais da Ilha de Santa Catarina, como: Itacorubi, Córrego Grande, Agronômica e Saco Grande, e uma em área continental, situada no bairro Coqueiros. O tempo de atividade das lavanderias se mostrou bem diverso, três delas funcionam há, pelo menos, um (01) ano no mercado, e as outras três (03) estão situadas, comercialmente, há mais de 10 anos, dentre essas últimas, destaca-se uma que oferece atividades profissionais nessa área há 21 anos (L05). Ainda, os entrevistados foram convidados a descrever brevemente o histórico da lavanderia, em seguida, foram questionados sobre os serviços de cuidados têxteis especializados por eles oferecidos. Foi visto que todas as lavanderias oferecem serviços completos de: lavagem à seco, lavagem à úmido e lavagem à água, com uso de alvejante, se necessário; secagem natural ou em tambor; e passadoria. Ainda, quatro lavanderias (L01, L02, L04, L05) oferecem serviços de tinturaria; e três lavanderias (L02, L05, L06) mantêm parcerias com ateliês de costura para prestação de serviços de pequenos reparos têxteis. Todavia, é necessário enfatizar que as realizações de tais serviços não são em conjunto com a lavanderia e, sim, em locais terceirizados. A lavanderia, nesse caso, se limita a recepcionar os clientes, analisar e identificar os artigos têxteis, que são, portanto, encaminhados para os serviços terceirizados para que tais procedimentos, específicos, sejam realizados. Em algumas situações de reparos têxteis, a lavanderia se restringe a repassar o contato de seus parceiros aos seus clientes. Os dados completos obtidos nessa categoria podem ser apreciados no Quadro 2. 


\begin{tabular}{|c|c|c|c|c|}
\hline ID & $\begin{array}{l}\text { LOCALIZAÇÃO } \\
\text { LAVANDERIA }\end{array}$ & $\begin{array}{l}\text { TEMPO DE } \\
\text { ATIVIDADE* }\end{array}$ & BREVE HISTÓRICO & $\begin{array}{l}\text { PRINCIPAIS } \\
\text { SERVICOS }\end{array}$ \\
\hline L01 & Itacurubi & 14 anos & $\begin{array}{l}\text { Iniciaram em 2002, e estão } \\
\text { desde } 2013 \text { com a atual ge- } \\
\text { rência. Tem como propósito } \\
\text { o atendimento doméstico. }\end{array}$ & $\begin{array}{l}\text { Lavagem; Secagem; } \\
\text { Passadoria; Tintura- } \\
\text { ria (terceirizado). }\end{array}$ \\
\hline L02 & Saco Grande & 2 anos & $\begin{array}{l}\text { Iniciaram em } 2014 \text { e contam } \\
\text { atualmente com duas lojas, } \\
\text { uma no bairro Itacorubi } \\
\text { e outra no Saco Grande, } \\
\text { ambas com propósito de } \\
\text { atendimento doméstico. }\end{array}$ & $\begin{array}{l}\text { Lavagem; Secagem; } \\
\text { Passadoria;Tintu- } \\
\text { raria (terceirizado); } \\
\text { Conserto de Rou- } \\
\text { pas (terceirizado). }\end{array}$ \\
\hline L03 & Córrego Grande & 10 anos & $\begin{array}{l}\text { Iniciaram seus serviços em } \\
2006 \text { e conta atualmente } \\
\text { com duas lojas, uma matriz, } \\
\text { no bairro Córrego Grande } \\
\text { e um ponto de coleta no } \\
\text { bairro Centro. }\end{array}$ & $\begin{array}{l}\text { Lavagem; Secagem; } \\
\text { Passadoria. }\end{array}$ \\
\hline L04 & Córrego Grande & 1 ano & $\begin{array}{l}\text { Filial franqueada de uma } \\
\text { nova marca, surgida em } \\
\text { Santa Catarina, de um grupo } \\
\text { antigo nacional. Iniciaram } \\
\text { seus serviços em } 2015 \text {. }\end{array}$ & $\begin{array}{l}\text { Lavagem; Secagem; } \\
\text { Passadoria; Tintura- } \\
\text { ria (terceirizado). }\end{array}$ \\
\hline L05 & Agronômica & 21 anos & $\begin{array}{l}\text { Iniciaram em 1995, com } \\
\text { uma lavanderia pequena, } \\
\text { somente com máquinas do- } \\
\text { mésticas. Foram adquirindo } \\
\text { equipamentos profissionais } \\
\text { e expandindo. Atualmente } \\
\text { contam com } 5 \text { filiais dis- } \\
\text { tribuídas em toda Grande } \\
\text { Florianópolis. }\end{array}$ & $\begin{array}{l}\text { Lavagem; Secagem; } \\
\text { Passadoria; Tintu- } \\
\text { raria; Conserto de } \\
\text { Roupas (terceiriza- } \\
\text { do). }\end{array}$ \\
\hline L06 & Coqueiros & 3 anos & $\begin{array}{l}\text { Filial franqueada de uma } \\
\text { marca renomada de um } \\
\text { grupo internacional com } \\
\text { mais de } 45 \text { anos de ativida- } \\
\text { des no ramo. Presente há } 20 \\
\text { anos em operação no Brasil, } \\
\text { possuem diversas lojas } \\
\text { em operação em território } \\
\text { nacional. }\end{array}$ & $\begin{array}{l}\text { Lavagem; Secagem; } \\
\text { Passadoria; Con- } \\
\text { serto de Roupas } \\
\text { (terceirizado). }\end{array}$ \\
\hline
\end{tabular}

Fonte: Elaborado pelos autores, 2016.

* Considerado em anos a partir da abertura da lavanderia enquanto ponto comercial, sem considerar tempo de existência da franquia, quando for o caso.

\subsection{Percepções e Interações Interfaciais}

Na abordagem referente às percepções e às interações interfaciais dos usuários 
profissionais com as etiquetas técnicas de manutenção e conservação têxtil, tais usuários foram questionados sobre os procedimentos realizados na primeira interação com o cliente, isto é, se, nessa etapa, eles observam as etiquetas têxteis dos artigos recebidos pelos clientes. Todos foram unânimes em afirmar que tal prática de observação das etiquetas é frequente e constante. Aparentemente, todo processo de interação entre cliente-lavanderia se inicia com a observação da etiqueta. É a partir dela, que a lavanderia pode dialogar com o cliente, expressando, indicando ou ainda sugerindo os procedimentos de manutenção e conservação mais adequados para o artigo têxtil, de maneira a oferecer melhores configurações e opções de seus serviços.

As interações entre cliente-lavanderia ocorrem facilmente caso a etiqueta esteja afixada ao produto, todavia, se tornam nebulosas, quando esta é descartada previamente. Para os artigos têxteis que não possuem a etiqueta, o indivíduo L02 afirmou que é como se a lavanderia estivesse com a 'luz apagada', uma vez que sem ela, não há como saber quais são os procedimentos de manutenção e conservação adequados. Nesse sentido, como a lavanderia prestará bons serviços? Segundo os profissionais da lavanderia, essa situação é ainda mais incômoda quando o artigo têxtil é considerado 'delicado', ou seja, artigos que não possuem características têxteis ordinárias ou facilmente identificadas pelo exame visual. Nesse caso, o artigo têxtil considerado delicado, pode ter detalhes ou aplicações específicas, como: bordados, estampas, e pode ser confeccionado num tecido distinto ou ser um traje social. Indiferente dessas categorizações, alguns usuários profissionais (L01, L02, L03, L05) foram convictos em dizer que a falta de etiqueta nesse tipo de produto é a pior das circunstâncias, uma vez que são artigos que necessitam de cuidados têxteis específicos para os quais a lavanderia não pode oferecer adequadamente seus serviços, por não saber quais os procedimentos de manutenção e conservação são apropriados para esses artigos. O fato dos clientes considerarem a realização dos cuidados têxteis de artigos considerados 'delicados' pelas lavanderias já sugere que a procura desse serviço especializado se dá pela não garantia da realização dos procedimentos de manutenção e conservação de maneira doméstica, justamente devido aos aspectos têxteis diferenciados do artigo.

Quando os artigos têxteis não possuem as etiquetas técnicas, os usuários profissionais disseram que, frequentemente, decidem os procedimentos de manutenção e conservação pela prática e conhecimento adquirido no ramo de lavanderias, ou seja, pelo toque do tecido, o tipo de artigo, entre outros aspectos. O indivíduo L02 comentou que, nesse caso, além de se guiar com base na experiência profissional, costuma realizar procedimentos de lavagem profis- 
sional à seco ou à úmido, por serem procedimentos mais 'seguros'. Com tais procedimentos de lavagem, esses profissionais são capazes de realizar testes com produtos químicos em uma pequena área, na parte interna do artigo, para saber como este irá reagir, evitando assim, a probabilidade de ocorrência de danificações. Já, o indivíduo L05, explicou que artigos sem etiquetas, frequentemente, passam por uma segunda avaliação técnica com a gerente dos processos de manutenção e conservação têxtil.

A utilização de uma segunda opinião é uma prática exercida também pelo indivíduo L04, porém, nos processos que envolvem tingimento. Diante disso, o artigo sem etiqueta é encaminhado para um laboratório químico - fornecido pela franquia - que analisa a composição de fibra têxtil, para então avaliar se o artigo pode sofrer tingimento ou não. Essa verificação químico-física da fibra têxtil é feita, também, pelos profissionais da lavanderia do indivíduo L01. Entretanto, a necessidade de tais verificações em laboratório ou de avaliações técnicas é considerada um processo moroso, o que poderia, facilmente, ser evitado caso o artigo estivesse com a etiqueta afixada.

Em relação à responsabilização da lavanderia caso algum artigo têxtil sem a etiqueta seja danificado nos procedimentos de manutenção e conservação, todos os profissionais afirmaram que a lavanderia se isenta de responsabilidade nessas situações. Habitualmente, todas elas possuem mecanismos para tais casos, como termos de responsabilidades, protocolos de isenção e comandas de serviços que devem ser assinadas pelo cliente, absolvendo à lavanderia na ocorrência de quaisquer danificações devido aos procedimentos incorretos ou inadequados aplicados aos artigos sem etiquetas. Quando questionados sobre a frequência das ocorrências de danificações em artigos nessa situação, quatro profissionais (L02, L04, L05, L06) afirmaram que as danificações são ocasionais e mais comuns em artigos considerados 'delicados', dois profissionais disseram que as danificações ocorrem raramente (L01, L03), inclusive, um deles (L01), afirmou que as danificações são mais frequentes nos processos de tingimento. A principal causa de danificações, comentada por quatro profissionais (L01, L03, L04, L05), é a relação de manutenção e conservação de materiais com características têxteis diferenciadas num mesmo artigo, como por exemplo, artigos têxteis fabricados com partes bicolores, que possuem característica de fixação de corante diferenciado, ou aqueles que quando submetidos aos processos de lavagem podem soltar pigmento, 'migrando' a coloração para outras partes da peça.

Em relação à capacidade de identificação dos cuidados têxteis do artigo pela 
disposição, somente, da informação de composição têxtil, cinco profissionais afirmaram que é possível identificar os procedimentos adequados para cada tipo de material, entretanto essa informação deve, também, ser disponibilizada pela interface da etiqueta, segundo os profissionais L01, L03 e L04. Somente um profissional (L06), colaborador de uma franquia, é orientado a observar somente a simbologia de manutenção e conservação têxtil, ou seja, em nenhum momento, ele estabelece como base a informação de composição têxtil. Ainda, o profissional L05 salientou que sem a disposição da informação de composição têxtil na etiqueta, apesar da experiência adquirida no ramo de lavanderias e conhecimentos de materiais e tecidos, é impossível afirmar com certeza, somente pela inspeção visual e tátil, a composição de fibra têxtil exata de um determinado artigo. Os profissionais L02, L04 e L05 comentaram que mesmo possibilitados em realizar os procedimentos de cuidados têxteis somente com a informação de composição têxtil, preferem utilizar a simbologia de manutenção e conservação têxtil, quando o artigo dispõe dessa simbologia, por ser a referência principal e essencial para o repasse dos procedimentos corretos a serem executados. Além da simbologia têxtil, a informação de composição têxtil se torna indispensável, também, na oferta de serviços de tingimento disponibilizados pelas lavanderias dos profissionais L01, L02, L04 e L05, pois, normalmente, para fixação completa do corante utilizado nos processos de tingimento, o material tem que ser constituído de no mínimo $80 \%$ fibras naturais.

A respeito das práticas de incentivo das lavanderias para seus clientes manterem as etiquetas afixadas aos seus artigos têxteis, quatro profissionais (L01, L02, L03, L06) afirmaram que há o incentivo constante, principalmente dos clientes que costumam descartar as etiquetas, que de acordo com o profissional L06, são a maioria. Dois profissionais (L04, L05) afirmaram não incentivar os clientes a manterem afixadas as etiquetas nos artigos têxteis, um deles, o indivíduo L05, comentou não possuir esse hábito, pois, a etiqueta, enquanto instrumento de auxílio às lavanderias, está sendo um incômodo devido à apresentação de informações incorretas e incoerentes.

Nessa sequência, o profissional L01 comentou que há, também, um incentivo para que os clientes guardem as etiquetas, caso essas sejam descartadas devido ao desconforto físico, ou anotem as informações nelas contidas em outros meios. A conscientização da importância da permanência das etiquetas nos artigos têxteis só ocorre quando o cliente precisa realizar os cuidados têxteis profissionais de um determinado artigo com valor simbólico elevado em que a etiqueta foi retirada e descartada. Nesse caso, o cliente precisa confiar na experiência dos profissionais das lavanderias para manter e conservar seu artigo têx- 
til, situação essa, que causa insegurança, conforme a colocação do profissional L02. Diante dessa perspectiva, quando questionados sobre possíveis distinções nos procedimentos de manutenção e conservação têxtil de artigos com valores simbólicos de marca atrelados, houve divergência nas respostas dos usuários profissionais. Três indivíduos (L03, L04, L06) afirmaram que não há distinções nesse sentido por parte das lavanderias, enquanto os outros três indivíduos (L01, L02, L05) foram enfáticos em dizer que os tratamentos são diferenciados de acordo com o valor simbólico da marca.

Apesar da divisão das respostas obtidas pelos profissionais, mesmo entre os que afirmaram não haver distinção nos processos realizados pela lavanderia, quase todos comentaram que a diferenciação ocorre principalmente na interação entre cliente e lavanderia, pois, é perceptível que os clientes possuem um apego e carinho maior pelos artigos com valor simbólico de marca, e que, consequentemente, possuem uma preocupação maior com os cuidados têxteis desses artigos, conforme apontado pelos profissionais L03 e L04. Ainda, os profissionais L04 e L05 mencionaram que a lavanderia lida com a intimidade das pessoas, com os 'sentimentos' e com o carinho que os indivíduos possuem por cada artigo têxtil, seja por seus atributos práticos (conforto), estéticos (beleza) ou simbólicos (marca). 0 profissional L05 enfatiza ainda, que artigos casuais, do dia a dia, têm seus cuidados e tratamentos têxteis, frequentemente, realizados de maneira doméstica, e disse que a procura das lavanderias, para realização de procedimentos de manutenção e conservação, é feito, na maioria das vezes, para cuidados de artigos têxteis que os clientes possuem um 'apego' maior.

Nesse sentido, a maioria dos profissionais (L02, L04, L05, L06) percebe que as etiquetas têxteis são mantidas mais frequentemente em artigos com valor simbólico de marca incorporado. O indivíduo L06 comenta que, dificilmente, aparecem artigos têxteis de marca, sem a etiqueta afixada. Ainda, os profissionais L02 e L05 associam esse hábito ao fato de as etiquetas de artigos têxteis com valor simbólico de marca, principalmente os itens importados, possuem configuração morfológica, disposição das informações e posicionamento diferenciados, consideradas mais adequadas, compreensíveis e padronizadas. Para o indivíduo L02, com as etiquetas de tais artigos é muito mais 'fácil de trabalhar', justamente pelo caráter de clareza das informações que estão dispostas nelas. O profissional L05 comenta que essa diferenciação entre as etiquetas de artigos nacionais e importados acontecem devido às regulamentações e às fiscalizações serem mais severas em outros países. Como a finalização da abordagem se refere às interações entre usuários profissionais e etiquetas têxteis, foi questionado a esses usuários se percebem algum 
segmento específico de artigos têxteis nos quais as etiquetas são descartadas mais comumente. Entre os segmentos citados pelos profissionais, todos foram concernentes ao universo do vestuário, sendo os artigos mais citados: camisetas, vestidos, calça, trajes sociais e artigos com características de transparência. Os profissionais L03 e L04 comentaram que não conseguem perceber nenhum segmento distintivo, porém, salientaram que observam o descarte das etiquetas mais, frequentemente, em artigos têxteis de indivíduos do gênero feminino do que do gênero masculino. Eles atribuíram essa característica mais comum ao gênero feminino, devido ao vestuário feminino ser composto de peças ajustadas ao corpo, nesse sentido, o desconforto físico é visto como o principal motivo de descarte das etiquetas.

Em contrapartida, foram questionados acerca da percepção de segmentos específicos de artigos têxteis em que as etiquetas são frequentemente mantidas afixadas. Nesse caso, os profissionais observaram que as etiquetas são mantidas em artigos de vestuário com modelagens amplas, ou seja, não ajustadas ao corpo como blazers e casacos, e em artigos que não são do uso de vestuário, como por exemplo, artigos de cama, mesa e banho, acessórios, entre outros. Somente o profissional L06 disse não perceber nenhum segmento específico, e disse, também, que a maior parte dos artigos têxteis é apresentada à lavanderia sem as etiquetas afixadas.

Os dados dos principais questionamentos, referentes a abordagem acerca das percepções e interações interfaciais entre usuários profissionais e etiquetas têxteis, podem ser visualizados no Quadro 3.

Quadro 3 - Dados dos principais questionamentos da abordagem relativa às percepções e interações interfaciais usuário-artefato

\begin{tabular}{|l|c|c|c|c|c|c|}
\hline & L01 & L02 & L03 & L04 & L05 & L06 \\
\hline $\begin{array}{l}\text { Profissionais que observam frequentemente as } \\
\text { etiquetas }\end{array}$ & $\mathrm{X}$ & $\mathrm{X}$ & $\mathrm{X}$ & $\mathrm{X}$ & $\mathrm{X}$ & $\mathrm{X}$ \\
\hline $\begin{array}{l}\text { Profissionais que incentivam os clientes a manterem } \\
\text { as etiquetas afixadas ao artigo têxtil }\end{array}$ & $\mathrm{X}$ & $\mathrm{X}$ & $\mathrm{X}$ & & & $\mathrm{X}$ \\
\hline $\begin{array}{l}\text { Profissionais que consideram a frequência de ocor- } \\
\text { rências de danificações, devido à falta de etiqueta, } \\
\text { ocasional }\end{array}$ & & $\mathrm{X}$ & & $\mathrm{X}$ & $\mathrm{X}$ & $\mathrm{X}$ \\
\hline $\begin{array}{l}\text { Profissionais que não se responsabilizam por danifi- } \\
\text { cações devido à falta da etiqueta }\end{array}$ & $\mathrm{X}$ & $\mathrm{X}$ & $\mathrm{X}$ & $\mathrm{X}$ & $\mathrm{X}$ & $\mathrm{X}$ \\
\hline $\begin{array}{l}\text { Profissionais para qual a informação de composição } \\
\text { têxtil é essencial }\end{array}$ & $\mathrm{X}$ & $\mathrm{X}$ & & $\mathrm{X}$ & $\mathrm{X}$ & \\
\hline $\begin{array}{l}\text { Profissionais que diferenciam os cuidados dos artigos } \\
\text { têxteis com valor simbólico de marca incorporado }\end{array}$ & $\mathrm{X}$ & $\mathrm{X}$ & & & $\mathrm{X}$ & \\
\hline
\end{tabular}

Fonte: Elaborado pelos autores, 2016. 


\subsection{Percepções das Caraterísticas Morfológicas e Informações Regulamentadas}

Em relação à abordagem referente às percepções e às interações interfaciais, entre usuários profissionais e etiqueta têxtil, acerca das características morfológicas e das informações normatizadas dessas etiquetas, foi questionado aos profissionais das lavanderias se realizavam cursos preparatórios para a compreensão dos processos de manutenção e conservação têxtil, bem como para o entendimento das informações presentes nas etiquetas, especificamente, da simbologia e da composição têxtil. Os profissionais das lavanderias de grandes franqueados, como o indivíduo L04 e L05, comentaram que, frequentemente, são oferecidos cursos preparatórios e treinamentos de tais procedimentos. Dois profissionais (L03, L04) afirmaram que tais cursos e treinamentos são oferecidos somente aos gerentes ou aos supervisores da lavanderia, sendo esses os responsáveis pelo repasse dos conteúdos para toda equipe. Por fim, os profissionais (L01, L02), também, sócios-proprietários de suas lavanderias, disseram não oferecer, nem participar, de cursos e/ou treinamentos.

Especificamente a respeito da simbologia têxtil e de sua normatização, instrumento principal para a oferta dos serviços prestados pelas lavanderias, quatro profissionais (L03, L04, L05, L06) afirmaram que as lavanderias em que atuam possuem a normatização de simbologia têxtil elaborada pela ABNT NBR NM ISO 3758 (2013). Coincidentemente, os mesmos profissionais que não participam de cursos e treinamentos preparatórios, L01 e L02 comentaram, também, não possuir a norma e disseram que só tem conhecimento de tal assunto a partir de informações disponíveis na internet. Nessa perspectiva, todos os profissionais afirmaram utilizar informes visuais e auxílio de gráficos e tabelas orientativas acerca dos significados da simbologia têxtil presente nas etiquetas. Normalmente, esses informes estão disponibilizados nos espaços próximos ao maquinário, utilizado para realização dos procedimentos de manutenção e conservação têxtil. Contudo, tais informes estão dispostos, também, nos balcões de atendimentos de algumas lavanderias (L03, L04, L06) de modo a conscientizar e alfabetizar visualmente os próprios clientes.

Em estudo anterior realizado pela pesquisadora (SCHNEIDER; SANTOS; SANTOS, 2015) verificou-se que, domesticamente, a compreensibilidade da simbologia de manutenção e conservação têxtil é prejudicada pela não padronização de alguns dos equipamentos utilizados nesses processos, como o ferro na 
passadoria e/ou a máquina lavadora na lavagem ${ }^{1}$. De modo a verificar essa situação, também, no ambiente de cuidados têxteis profissional, foi questionado a esses usuários se o maquinário utilizado pela lavanderia nos procedimentos de manutenção e conservação têxtil — lavadoras, secadoras, ferros — segue o especificado pela normatização, com padronização na seleção das temperaturas e dos tipos de processos. Nesse caso, todos os profissionais afirmaram que as lavadoras industriais possuem indicação de temperatura $-30^{\circ}, 40^{\circ}, 60^{\circ} \mathrm{e}$ $95^{\circ}$ - , porém, não dispõem dos tipos de processos - normal, suave ou muito suave. O mesmo acontece para as secadoras e os ferros, contudo, três profissionais (L01, L02, L03) comentaram que nesses equipamentos a indicação de temperatura é determinada por 'normal' ou 'alta' nas secadoras; ou pelo tipo de tecido, 'algodão', 'linho', 'seda', entre outros, nos ferros de passar.

Percebe-se que mesmo nos equipamentos industriais, utilizados durante os cuidados têxteis profissionais, não há uma clara padronização entre maquinário e informações normatizadas. Essa condição dificulta o entendimento e, consequentemente, a realização dos procedimentos adequados de manutenção e conservação têxtil, principalmente, acerca da falta de definições específicas sobre o significado de um processo 'normal', 'suave' ou 'muito suave.' O processo 'normal', estabelecido por uma determinada máquina lavadora, pode não ser o processo 'normal' de outra, assim como, a temperatura categorizada como 'algodão', num ferro de passar, pode não ser a mesma temperatura categorizada como 'algodão' em outro. O profissional L02 disse que, apesar da orientação da etiqueta seguir rigorosamente a normatização, a lavanderia muitas vezes tem que se guiar pela dedução, tentando compreender no próprio maquinário quais os procedimentos coerentes com as informações dispostas pela etiqueta. O funcionamento da simbologia de cuidados têxteis normatizada nas etiquetas, enquanto informação, e sua transposição por meio do maquinário utilizado para realização dos procedimentos, não parece seguir um mesmo padrão ou lógica, tornando a etiqueta têxtil, em alguns momentos, superficial até mesmo para as lavanderias.

A respeito das diferenças de interpretação dos cuidados têxteis de artigos com etiquetas, que possuem as informações de manutenção e conservação têxtil

1 Muitos aparelhos eletrodomésticos regulamentados não possuem indicação de temperaturas específicas, informação imprescindível para realização da maioria dos processos de lavagem, passadoria e secagem. Normalmente, o ferro de passar divide as categorias de alteração de temperatura pelo tipo de tecido, enquanto a máquina lavadora seleciona o processo a partir do tipo de lavagem ou do tipo do artigo têxtil, como roupas delicadas, roupas brancas, roupas encardidas, entre outros. 
descritivas por extenso, além da simbologia, praticamente, todos os profissionais se disseram indiferentes, por se basearem quase, exclusivamente, pelos símbolos gráficos. O profissional L01 comentou que raramente aparecem artigos têxteis com esse tipo de etiqueta, muito devido ao seu tamanho, que provavelmente causa maior desconforto físico. Somente o profissional L02 afirmou preferir as informações de cuidados têxteis de maneira descritiva, principalmente em idioma português, pois, isso facilita a interpretação dos processos pelos colaboradores com menor grau de instrução. Ainda, todos os profissionais disseram não conferir a compatibilidade das informações descritivas com as da simbologia.

Quando questionados sobre a confiabilidade das informações técnicas presentes nas etiquetas, todos os profissionais foram resolutos em dizer que as informações das etiquetas não são confiáveis. Os entrevistados disseram que, frequentemente, essas informações se apresentam incompletas, incorretas e/ ou incoerentes no que diz respeito à composição e procedimentos de manutenção e conservação têxtil de um determinado artigo têxtil. Os profissionais L03 e L05 comentaram que devido ao caráter obrigatório das etiquetas técnicas, as indústrias optam por afixar qualquer etiqueta aos artigos, não considerando as características específicas de cada modelo. Acredita-se que essa situação, provavelmente, é consequência da efemeridade do sistema de moda estabelecido, atualmente. Com grandes quantidades de modelos e coleções lançadas a cada estação, a preocupação com as etiquetas técnicas é deixada de lado, em favorecimento de outros tipos de etiquetas com maior apelo visual e institucional. Além disso, com a importação acelerada de artigos têxteis de outros países, principalmente da China, e do surgimento progressivo de novos materiais têxteis, essa condição é intensificada, uma vez que a falta de controle dos processos produtivos dificulta o acesso às informações pertinentes para o repasse adequado ao usuário.

Nesse sentido, todos os profissionais relataram que, repetidamente, percebem etiquetas de uma mesma marca apresentando etiquetas idênticas para artigos com características têxteis diferenciadas. Nessas condições, se torna impossível para o profissional avaliar e distinguir quais informações contidas na etiqueta são realmente verdadeiras. Entretanto, os profissionais comentaram que apesar da experiência e da prática adquirida no ramo de lavanderias, nem sempre é tão simples fazer avaliações certeiras. Nesse caso, quando ocorrem danificações nos artigos têxteis devido à realização de procedimentos de manutenção e conservação incorretos, conforme as informações apresentadas nas etiquetas, 
quatro profissionais (L02, L03, L05, L06) afirmaram que o protocolo das lavanderias é encaminhar o determinado artigo para análise na Associação Nacional de Empresas de Lavanderias - ANEL ${ }^{2}$. A ANEL realiza análises laboratoriais e fornece um parecer técnico acerca dos procedimentos de manutenção e conservação realizados, comprovando se tais procedimentos convergem para a informação indicada pela etiqueta e se essa informação é adequada para as propriedades têxteis do artigo em questão. Atestando que a lavanderia seguiu corretamente os procedimentos descritos na etiqueta e não tem responsabilidade pelos danos ocorridos, fica a cargo do cliente reivindicar com o fabricante.

Diante da possibilidade de reclamações por parte dos clientes, os profissionais L03, L04 e L05 percebem que muitos fabricantes de artigos têxteis procuram se resguardar previamente das responsabilidades de eventuais danos causados devido aos procedimentos de manutenção e conservação têxtil realizados. Nesse sentido, os fabricantes indicam, por meio das etiquetas, que nenhum dos procedimentos de lavagem, nem em água, à úmido ou à seco, podem ser realizados. Por não saberem exatamente quais procedimentos são adequados e permitidos para determinado artigo têxtil e evitar indicações de informações aleatórias passíveis de reclamações posteriores, os fabricantes preferem indicar na etiqueta que nenhum procedimento de manutenção e conservação é permitido. Essa manobra, praticada também em artigos com cuidados têxteis considerados simples, estabelece uma deslealdade com o usuário profissional, que é questionado pelo cliente acerca da impossibilidade de lavagem, e não pode oferecer seus serviços de cuidados têxteis de maneira segura e amparada.

Além disso, nessas situações, caso ocorram danificações no artigo têxtil, as pessoas tendem a atribuir a responsabilidade por meio de uma relação causal de sucessão, conforme apontado por Norman (2006). No universo das etiquetas têxteis, a percepção da autoria dos erros se torna complexa. Nesse sentido, quando os procedimentos de manutenção e conservação de um artigo têxtil são realizados na lavanderia, e alguma danificação é causada devido aos processos utilizados pela lavanderia, mesmo esta seguindo orientações da etiqueta, automaticamente a responsabilidade de danos é atribuída a ela, em vez da responsabilidade ser atribuída ao fabricante, o qual disponibilizou uma etiqueta com informações incorretas e inadequadas. Dessa forma, os fabricantes se favorecem dessa situação, e, justamente por isso, não se interessam na modificação e/ou elaboração 2 A ANEL oferece serviços de análise e elaboração de parecer técnico de artigos têxteis que, após a lavagem, limpeza ou beneficiamento — informações disponibilizadas pela etiqueta realizados pelas lavanderias apresentaram alguma danificação. Mais informações podem ser consultadas em: \&lt;http://anel.com.br/parecer-tecnico/\&gt;. Acesso em: 15 mar. 2016. 
da estrutura de uma etiqueta mais fidedigna para seus usuários, porque são conscientes de que, qualquer danificação ocorrente, a responsabilidade será atribuída, primeiramente, ao usuário, o qual não realizou os procedimentos descritos. Nesse sentido, os usuários profissionais são mais prejudicados, pela agravante perda de clientela.

Finalizando essa abordagem, a respeito da indelebilidade das etiquetas, característica regulamentada pelo CONMETRO (2008), quando questionados, todos os profissionais foram unânimes em afirmar que as etiquetas se desgastam frequentemente e facilmente, principalmente, os artigos têxteis que são submetidos a muitos procedimentos de manutenção e conservação têxtil. Os profissionais observaram, também, que, conforme o passar do tempo, as etiquetas, em seus atributos materiais, ficam com acabamento superficial deteriorado, esfacelado, bem como a impressão fica desbotada e apagada. Nesse sentido, fica evidente, a despreocupação projetual da etiqueta por parte das indústrias têxteis, lembrando que a qualidade de indelebilidade é regulamentada. Assim, atributos relativos aos materiais e aos processos de produção, utilizados para elaboração de uma etiqueta, deveriam ser investigados e testificados de modo a oferecer opções configurativas com melhores aspectos de durabilidade.

\subsection{Percepção da importância e Funcionalidade}

A respeito da funcionalidade e importância das etiquetas técnicas de manutenção e conservação têxtil para os usuários profissionais, unanimemente, todos consideraram as etiquetas essenciais para prestação dos serviços ofertados pela lavanderia. É a partir da etiqueta que os procedimentos específicos de manutenção e conservação têxtil de cada artigo têxtil são elucidados, na identificação do tipo de tecido, da composição da fibra têxtil, dos produtos químicos ideais a serem utilizados, ou seja, todas as orientações técnicas de processamento de cuidados dos artigos têxteis. O profissional L03 afirmou que as etiquetas, nesse caso, são primordiais na tomada de decisão sobre os procedimentos de manutenção e conservação adequados para cada artigo. Ainda, o profissional L04 salientou que com a presença da etiqueta, a lavanderia se sente mais preparada e segura para prestar seus serviços aos clientes.

Nessa perspectiva, quando questionados quanto aos prejuízos causados às lavanderias devido à despreocupação projetual das etiquetas técnicas de manutenção e conservação têxtil, novamente, todos os profissionais consideraram que as lavanderias são as maiores prejudicadas, principalmente nos casos em que as etiquetas apresentam informações incorretas, incompletas ou incoeren- 
tes. Os profissionais L03, L04, L05 e L06 salientaram que, frequentemente, perdem clientes devido à despreocupação dos fabricantes em oferecer etiquetas com informações adequadas. Ainda, o profissional L06 criticou a preocupação projetual das indústrias têxteis com outros tipos de etiquetas, como a informacional e a promocional, e questionou o porquê das etiquetas técnicas, consideradas mais relevantes para o usuário profissional, serem projetadas e fabricadas da forma mais 'baratinha'. Esse mesmo profissional salientou que um dos maiores contratempos encontrados pelas lavanderias são, contraditoriamente, as etiquetas têxteis. Para esse entrevistado, as etiquetas que deveriam servir enquanto instrumento eficaz no repasse das informações necessárias para prestação dos serviços das lavanderias, acabam se tornando uma complicação.

\section{Considerações Finais}

O objetivo dessa pesquisa residiu na análise exploratória e aprofundada a respeito das interações entre usuários profissionais e etiquetas técnicas de manutenção e conservação têxtil e da consequente verificação da sua importância informacional para prestação dos serviços de cuidados têxteis especializados. Por meio de entrevistas com os usuários profissionais evidenciaram-se as dificuldades relatadas por esse grupo em suas interações estabelecidas com as etiquetas. Constatou-se que para a oferta dos serviços referentes aos cuidados têxteis especializados, realizados pelas lavanderias, a etiqueta técnica é considerada instrumento primordial. É a partir dela que os usuários profissionais podem disponibilizar o melhor de suas atividades especializadas, relativas aos procedimentos de manutenção, conservação e tingimento têxtil, aos seus clientes.

Como identificado pelos usuários profissionais, a retirada e o descarte das etiquetas dos artigos têxteis pelos usuários domésticos, assim como a presença de informações muitas vezes incorretas e incoerentes dificulta o entendimento dos processos adequados de cuidados têxteis, prejudicando a autonomia da lavanderia na prestação de um serviço considerado de qualidade. Além disso, há a insegurança frequente por parte dos usuários profissionais da ocorrência de danificações ou prejuízos aos artigos têxteis por eles cuidados e tratados. Obviamente, nesse caso, as interações entre usuário doméstico e profissional ou entre cliente e lavanderia são também afetadas, prejudicando possivelmente a imagem da lavanderia enquanto prestadora de serviços. Ainda, foi possível perceber a relevância atribuída, pelos usuários profissionais, às funções estéticas e simbólicas da etiqueta, evidenciada pela valorização dos atributos relacionados à aparência e valores de marca incorporados. 
Em relação à percepção dos usuários profissionais quanto aos possíveis aperfeiçoamentos projetuais nas etiquetas que pudessem facilitar e melhor a prestação dos serviços especializados oferecidos pela lavanderia, os profissionais convergem para a padronização estrutural da etiqueta. Apesar das normatizações e regulamentações existentes, muitas características morfológicas, como tamanho, localização, material, impressão, entre outros aspectos não são contempladas nesse sentido. Conforme observado pelos usuários profissionais, as qualidades projetuais das etiquetas são configuradas da maneira mais diversa possível, sendo assim, uma padronização mínima dessas características auxiliaria numa uniformização das etiquetas enquanto categoria visual. Com um melhor posicionamento e uma melhor localização nos artigos têxteis; um formato anatômico e confortável fisicamente; materiais e processos produtivos de qualidade e indeléveis; e uma simbologia regular, homogênea e correspondente ao maquinário utilizado, as etiquetas tendem a não ser descartadas pelo usuário doméstico e o usuário profissional, pode assim, prestar seus serviços de cuidados têxteis de maneira mais eficiente e eficaz, facilitando e aprimorando inclusive, as interações entre lavanderia e cliente.

\section{Referências Bibliográficas}

ASSOCIAÇÃO BRASILEIRA DE NORMAS TÉCNICAS - ABNT. NBR NM ISO 3758:

Têxteis: códigos de cuidados usando símbolos, Rio de Janeiro, 2013.

CALISIR, F; GUMUSSOY, C. A.; BOZDURGUT, N.; TOPALOGLU, H.; BAYRAKTAROGLU, E. Comprehension of care label symbols: effects of age, gender, and education level. In: Anais Engineering and Computer Science: Proceedings of the World Congress on Engineering and Computer Science, October 23-25, San Francisco: USA, p. 1190-1194, 2013.

CONSELHO NACIONAL DE METROLOGIA, NORMALIZAÇÃO E QUALIDADE INDUSTRIAL - CONMETRO. Resolução n 02, de 6 de maio de 2008. Dispõe sobre a aprovação do Regulamento Técnico Mercosul Sobre Etiquetagem de Produtos Têxteis. Disponível em: <http://www.inmetro.gov.br/legislacao/resc/pdf/ RESC000213.pdf>. Acesso em 29 nov. 2014.

FELTHAM, T.; MARTINR, L. A. Apparel care labels: understanding consumers' use of information. Marketing, v. 27, n. 3, p. 231-244, jun., 2006. 
GARCIA, L. J.; FERNANDES, C. A.; MERINO, E. A. D.; BRAVIANO, G. Usabilidade: a experiência do usuário com etiquetas de roupas. In: Anais II Conferência Internacional de Design, Engenharia e Gestão para a inovação - IDEMI, Florianópolis, 2012.

JONES, S. J. Fashion designer: manual do estilista. São Paulo: Cosac Naify, 2005.

JORDAN, P. W. An introduction to usability. London:Taylor \& Francis, 1998.

LIMA, M. A. D. S. Análise de Conteúdo: estudo e aplicação. Logos: Revista de Divulgação Científica da Ulbra, Canoas, v. 5, n. 1, p. 53-58, 1993.

MEIRELES, M. R. G.; CENDÓN B. V. Aplicação prática dos processos de análise de conteúdo e de análise de citações em artigos relacionados às redes neurais artificiais. Informação \& Informação, Londrina, v. 15, n. 2, p. 77-93, jul./dez., 2010.

MERWE, D.; BOSMAN, M.; ELLIS, S.; COLFF, N.; WARNOCK, M. Consumers' knowledge of textile label information: an exploratory investigation. International Journal of Consumer Studies, v. 38, p. 18-24, 2013.

MORAES, A.; MONT'ALVÃO, C. Ergonomia: conceitos e aplicações. Rio de Janeiro: A. de Moraes, 2003.

MUPFUMIRA, I. M.; JINGA, N. An investigation into care-label knowledge on textile products by Chesvingo residents in Masvingo Zimbabwe. Journal of Studies in Social Science, v. 3, n. 1, p. 80-100, 2013.

NORMAN, D. A. O design do dia a dia. Rio de Janeiro: Rocco, 2006.

NUNES, E. L. S.; TROTTA, T.; LICHESKI, L. C. Simbologia têxtil: aplicação e compreensibilidade. Ação Ergonômica: Revista da Associação Brasileira de Ergonomia, v. 9, n. 1, 2014.

PEREIRA, L. M.; ANDRADE, R. A.; PASCHOARELLI, L. C.; MENEZES, M. S. Análise da compreensão das informações contidas em etiquetas têxteis: um estudo de usabilidade. In: Anais $\mathbf{1 4}^{\circ}$ Congresso Internacional de Ergonomia e Usabilidade de Interfaces Humano-tecnologia - ERGODesign/USIHC, Joinville, 2014. 
PEZZOLO, D. B. Tecidos: histórias, tramas, tipos e usos. São Paulo: Editora SENAC São Paulo, 2007.

SIROTTI, G. The world of fashion labels and tags: thematic guide of the ultimate graphic collection. Modena: Happy Books, 2000.

STEYN, L.; MERWE, D.; ELLIS, S.; ZYL, S. D.; BOTHA, E. Consumer perceptions regarding labels on clothing and household textile products: a study in Gauteng. In: Anais 5th International Consumer Sciences Research Conference, Bonn, Germany, jul., 2011.

Jessica Schneider é Mestre em Design pela Universidade de Santa Catarina - UDESC (2016), ma área de concentração 'Métodos para os Fatores Humanos' e na linha de pesquisa de 'Interfaces e Interações Comunicacionais'. Possui graduação em Moda com Habilitação em Design de Moda pela Universidade do Estado de Santa Catarina - UDESC (2014) e titulação técnica em Imagem Pessoal com Habilitação em Estilismo da Confecção Industrial pelo Serviço Nacional de Aprendizagem Industrial de Santa Catarina - SENAI/SC (2008). Membro do Grupo de Pesquisa intitulado Núcleo de Estudos Semióticos e Transdisciplinares - NEST. Tem experiência na área de Moda com ênfase em Design de Moda e Tecnologia do Vestuário, atuando, principalmente, nos seguintes temas: Ergonomia, Usabilidade, Semiótica, Modelagem do Vestuário, Design de Superfície Têxtil e Tecnologia Têxtil.

Célio Teodorico dos Santos é Bacharel em Desenho Industrial pela Universidade Federal da Paraíba (1983). Mestre em Engenharia de Produção pela Universidade Federal de Santa Catarina - UFSC (1998), na área de Gestão do Design e do Produto. Doutorado em Engenharia Mecânica, na área de Projeto de Sistemas Mecânicos pela Universidade Federal de Santa Catarina - UFSC (2009). É Professor Adjunto do Departamento de Design e Professor Permanente do Programa de Pós Graduação em Design da Universidade do Estado de Santa Catarina - UDESC. Tem experiência na área de Desenho Industrial, com ênfase em Desenho Industrial, atuando, principalmente, nos seguintes temas: Pesquisa em Design, Design Industrial, Design Thinking, Ergonomia, consultoria eletro eletrônica, equipamentos hospitalares, projetos especiais e mobiliário. Pesquisador em Prospecções Metodológicas em Design, Linguagem do Produto, Design Thinking, Tecnologia Ubíqua e Perfasiva e

Recebido em: 15/08/2016 Aceito em:17/10/2016
Tecnologia Assistiva, Pesquisas Ergonômicas, Métodos Representacionais para o Ensino de Design. Pesquisas em Design de Interações. 